\title{
Plant-Based Synthesis of Silver Nanoparticles Using Aqueous Leaf Extract of Salvia officinalis: Characterization and its Antiplasmodial Activity
}

\author{
Kunle Okaiyeto $^{1,2} \cdot$ Heinrich Hoppe ${ }^{3} \cdot$ Anthony I. Okoh ${ }^{1,2}$
}

Received: 29 December 2019/Published online: 2 March 2020

(C) The Author(s) 2020

\begin{abstract}
In the present study, an aqueous leaf extract of Salvia officinalis was used to synthesize silver nanoparticles (AgNPs) and characterized with different techniques such as UV-vis spectroscopy, Fourier transform infrared (FTIR), X-ray diffraction (XRD), Scanning electron microscope (SEM), Energy dispersive X-ray spectroscopy (EDX), Transmission electron microscope (TEM) and thermogravimetric analysis (TGA). Subsequently, its cytotoxic effect against human cervix adenocarcinoma (HeLa) cells and antiplasmodial activity against Plasmodium falciparum were investigated. UV-vis spectrum of AgNPs displayed an absorption peak at $323 \mathrm{~nm}$ and TEM result revealed it to be spherical in shape with average size of $41 \mathrm{~nm}$. FTIR results highlighted the key bioactive compounds that could be responsible for the reduction and capping of AgNPs and XRD analysis showed its crystalline nature with a face-centered cubic (fcc) structure. The synthesized AgNPs was found to be less cytotoxic against HeLa cells line and demonstrated good antiplasmodial potential $\left(\mathrm{IC}_{50}=3.6 \mu \mathrm{g} / \mathrm{mL}\right)$. Findings from this study indicated that the AgNPs could serve as a template in the development of new drugs for the control of malaria and hence, further study is needed to identify and characterize the potent molecules that suppress the malaria parasite.
\end{abstract}

Keywords Salvia officinalis · Plant extract $\cdot$ Silver nanoparticles · Characterization · Antiplasmodial activity

\section{Introduction}

Nanotechnology has received global attention as an active area of research in material science and engineering because it explores a variety of promising techniques in these areas on a molecular level to fabricate metallic nanoparticles [1]. Among others, silver nanoparticles (AgNPs) are of leading interest in the present scenario due to their unique physicochemical properties such as

Kunle Okaiyeto

kokaiyeto@ufh.ac.za

1 South African Medical Research Council, Microbial Water Quality Monitoring Centre, University of Fort Hare, Alice 5700, South Africa

2 Applied and Environmental Microbiology Research Group (AEMREG), Department of Biochemistry and Microbiology, University of Fort Hare, Alice 5700, South Africa

3 Department of Biochemistry and Microbiology, Rhodes University, Grahamstown 6140, South Africa morphology structure, size distribution and surface charge, high catalytic property, high conductivity and thermal stability, and antibacterial effect [2]. In addition, their significant biomedical applications such as anticancer [3], antibacterial [4], mosquitocidal activity [5], antifungal [6], anti-inflammatory [7], anti-viral [8] have put them in the limelight in medicine.

Malaria is a life-threatening disease caused by parasites that are transmitted to people through the bites of infected female Anopheles mosquitoes [9]. In 2017, malaria cases from 87 countries were estimated to be about 219 million [10]. This parasitic disease is one of the leading causes of death especially in Africa. Despite the advanced efforts of WHO to eradicate malaria in the world, the disease continues to be one of the health problems facing people living in the developing countries. The occurrence of this disease is alarming, and compounding the problem is that parasitic infection does not produce a sterilising immune response, thus also leading to vaccination failure [11]. Malaria is a public health problem that has reduced the quality of life of 
individuals in developing countries, especially in the subSaharan Africa, and the only treatment option for this parasitic infection is chemotherapy [12]. In addition, despite the advances in research to understand the disease etiology and to find a permanent solution to overcome this disease, only a few antimalarial drugs have been developed and approved in the past three decades.

Cancer is the leading cause of death worldwide, responsible for an estimated value of about 9.6 million deaths in 2018 and among which, cervical cancer has been reported to be the fourth prevalence female cancer globally, which imposes serious threat to the public health $[13,14]$. Nearly about $90 \%$ of the 270000 cervical cancerrelated death cases documented in 2015 occurred in middle-income and low-income nations of the world where death rate is 18 times greater than the reported cases in the developed countries [15]. High-risk subtypes of the human papillomavirus (HPV) cause almost all cervix cancers and HPV screening and vaccination programmes are effective approaches in disease prevention [16]. Among the various cervical cancers, adenocarcinoma are the prevalence subtypes representing about $70 \%$ and $25 \%$ of all cervix cancers, respectively $[17,18]$. Regardless of the global efforts in improving its prevention and diagnosis, however, their treatment in the past years has been challenging due to cost and drug toxicity among other factors. Thus, the development of potent and effective antineoplastic drugs is one of the most swayed aims. Among the various approaches, the exploitation of natural products is one of the most successful methods to identify novel hits and leads [19].

Metallic nanomaterials can be synthesized via different approaches such as physical [20], chemical [1], and biological methods $[3,21]$. The biological mediated synthesis of silver nanomaterials is eco-friendly, non-toxic, simple and cost-effective as compared to the physical that required high energy and pressure and chemical method involves the use of toxic reagents that are toxic to human and constituent nuisance to the environment [22]. The biological substrates employed for fabricating metallic nanoparticles include; bacteria, fungi, algae and plants and among which, the latter appears to have gained more attention recently because of its superiority over other sources [23]. Plant-based nanoparticles are now an emerging area of research and have attracted high biotechnological consideration due to their different applications and besides, it does not involved complex protocols unlike microbes that involve preserving of sterile microbial cultures [24]. In addition, plants are widely distributed and easy availability, coupled with the absence of gene mutation make plants a resource of choice compared to microbes [25]. Thus, these salient features have made plant-mediated synthesis of nanoparticles to be propitious and promising compared to other methods $[26,27]$. However, the exact mechanism of plant-mediated nanoparticles synthesis is unclear and ambiguous, although several studies in the literature have reported that biomolecules in the plant extract such as flavonoids, alkaloids, glycosides, protein, phenolics etc. play a significant role in the reduction of metals ions to their respective nanoparticles. Furthermore, these biomolecules also act as capping and stabilizing agents for the biosynthesized nanoparticles [28-30]. In the literature, several plant extracts have been employed for the synthesis of silver nanoparticles and these examples include; Chrysanthemum indicum L. [31], Ceropegia thwaitesii [32], Datura stramonium [33], Cleome viscosa L. [34], Nepeta deflersiana [35] Berberis vulgaris [28], Myrtus communis [36] Kleinia grandiflora [37], Phyllanthus pinnatus [4].

For the time being, folkloric medicines have been the major and cheapest treatment option for malaria for several decades in Africa and the disease is often referred to as "poverty disease" since it majorly affects the less-privileged people in the society [38]. Hence, searching for new antimalarial drugs has been considered an important area in biotechnology. Folkloric herbs have been used for different purposes, such as medicine, nutrition, fragrances, flavouring, smoking, cosmetic, dying, repellents, charms, and industrial uses because of the pharmacologically active substances such as phenols, glycosides, alkaloids, terpenoids and flavonoids present in them [34]. Presently, about $60 \%$ of prescription drugs are based on natural compounds, particularly from plants [39]. Salvia officinalis is an evergreen perennial shrub with some medicinal and culinary [40]. The medicinal uses include; pain reliever, antioxidant, anti-inflammatory, antimicrobial and antiviral agents [41-43]. Some studies carried out by researchers from other countries have reported on S. officinalis-mediated silver nanoparticles synthesis [40, 41, 44].

To the best of our knowledge, this is the first study reporting on antiplasmodial activity of AgNPs from $S$. officinalis in South Africa. Therefore, in this present study, an aqueous extract of $S$. officinalis was used to synthesize AgNPs from $\mathrm{AgNO}_{3}$ precursor and subsequently, several techniques were used for its characterization and its cytotoxic effect on HeLa cells line was assessed prior to its antiplasmodial activity determination.

\section{Materials and Methods}

\section{Plant Identification and Extraction}

Salvia officinalis leaves were collected around the vicinity of University of Fort Hare, Alice campus in the Eastern Cape Province, South Africa. The plant identification was carried by Prof Christopher Cupido at the Department of 
Botany, University of Fort Hare and the plant was deposited in their herbarium with a specimen voucher (No: UFH/ 2019/001). The leaves were rinsed twice with tap water and subsequently with distilled water. Thereafter, the extraction was carried out as described by Bagherzade et al. [23] with minor modification. The leaves $(100 \mathrm{~g})$ were cut into smaller pieces and boiled in $100 \mathrm{~mL}$ of distilled water for $30 \mathrm{~min}$ at $60{ }^{\circ} \mathrm{C}$. The extract was allowed to cool down at room temperature, filtered through Whatman no. 1 filter paper and the extract was stored at $4{ }^{\circ} \mathrm{C}$ for further use.

\section{Biosynthesis of AgNPs}

The biosynthesis of AgNPs was carried out as described by Okaiyeto et al. [45] with a slight modification. Fifty millilitres $(50 \mathrm{~mL})$ of aqueous leaf extract of $S$. officinalis was added to $450 \mathrm{~mL}$ of $1 \mathrm{mM}$ silver nitrate $\left(\mathrm{AgNO}_{3}\right)$ solution and the mixture was stirred in the dark at room temperature for $1 \mathrm{~h}$ for complete synthesis. Thereafter, the colloidal mixture was centrifuged at $10,000 \mathrm{rpm}$ for $15 \mathrm{~min}$, at $15^{\circ} \mathrm{C}$ and the supernatant was collected for UV-vis analysis and the pellet was dispersed in distilled water, washed three times in order to remove any form of impurities that precipitated with AgNPs. Subsequently, purified AgNPs were oven-dried at $80{ }^{\circ} \mathrm{C}$ overnight and pulverised with mortar and pestle to obtain the powder.

\section{Characterization of Biosynthesized AgNPs}

The formation of AgNPs was confirmed after $1 \mathrm{~h}$ of synthesis by measuring its optical properties with UV-vis spectroscopy (PerkinElmer, Lambda 365) in the range of 280 to $500 \mathrm{~nm}$. Fourier transform infrared spectroscopy (Perkin-Elmer Universal ATR 100) was carried out in the range of $4000-400 \mathrm{~cm}^{-1}$ in order to determine the phytochemical compounds involved in the reduction of $\mathrm{AgNO}_{3}$ to AgNPs as well as those involved in the stabilization of AgNPs. The crystalline nature of AgNPs was determined with Bruker D8 advanced X-ray diffractometer. The surface morphology of AgNPs was elucidated with SEM (JOEL JSM-6390 LVSEM). The purity of the AgNPs was determined by EDX spectroscopy which was equipped with SEM. The size and the shape of the synthesized AgNPs was explored by TEM analysis (JOEL 12101). The thermal stability of AgNPs was carried out with TGA analyser.

\section{Cytotoxicity Effect of AgNPs Against HeLa Cells}

The cytotoxic effect of both the aqueous extract of $S$. officinalis and AgNPs was assessed on HeLa cells at $50 \mu \mathrm{g} /$
$\mathrm{mL}$ in $96-$ well plates for $48 \mathrm{~h}$ as described by Keusch et al. [46]. Emetine was used as positive control drug and the cells that survived AgNPs and extract exposure were quantified by incubation with resazurin and measuring its conversion to resorufin by fluorescence $\left(\mathrm{Exc}_{560} / \mathrm{Em}_{590}\right)$. Percentage viability of treated cells was calculated relative to fluorescence readings obtained with untreated control cells.

\section{Antiplasmodial Activity of AgNPs}

Antiplasmodial activity of AgNPs against $P$. falciparum (strain 3D7) was assessed in 96-well plates for $48 \mathrm{~h}$ following the description of Markler et al. [47] using parasite lactate dehydrogenase (pLDH) activity as a biomarker. Chloroquine, an antimalarial drug was used as a positive control. Percentage parasite viability was calculated relative to the pLDH activity in wells containing untreated control parasites.

\section{Statistical Analysis}

For the cytotoxicity assays, $\mathrm{IC}_{50}$ values were derived by non-linear regression analysis using GraphPad Prism.

\section{Results and Discussion}

\section{UV-Vis Spectroscopy Analysis}

Plant-mediated AgNPs synthesis provides a rapid, flexible, safe and economical synthesis route as compared to physical or chemical methods of AgNPs synthesis. UV-vis absorption spectroscopy analysis is one of the most sensitive, efficient and simple techniques that is commonly used at the preliminary stage to confirm the synthesis of AgNPs. In this study, change in colour of the aqueous leaf extract from pale yellow to dark brown was observed after its addition to $\mathrm{AgNO}_{3}$ solution which confirmed AgNPs formation after $1 \mathrm{~h}$ (Fig. 1). The colour change observed in $\mathrm{AgNO}_{3}$ could be due to the surface plasmon resonance (SPR) excitation at $323 \mathrm{~nm}$ that indicates the formation of AgNPs [45, 48, 49]. The appearance of dark-brown colour ascribed to the surface plasmon could be as a result of the collective oscillation of free electrons of the silver nanoparticles in resonance with the frequency of the light wave interactions causing the SPR band to appear in the visible and infrared region $[50,51]$. In the present study, it was observed that the aqueous leaf extract of $S$. officinalis contains some bioactive compounds that have the ability to reduce $\mathrm{AgNO}_{3}$ to $\mathrm{AgNPs}$ [52]. Hence, other characterization techniques are also necessary to further confirm the formation of AgNPs. Similarly, Shaik et al. [53] reported a 
Fig. 1 UV-vis spectroscopy analysis of AgNPs synthesized using aqueous leaf extract of $S$. officinalis $([\mathrm{a}-\mathrm{S}$. officinalis, b-aqueous leaf extract of $S$. officinalis, $\mathrm{AgNO}_{3}$ and AgNPs, respectively])
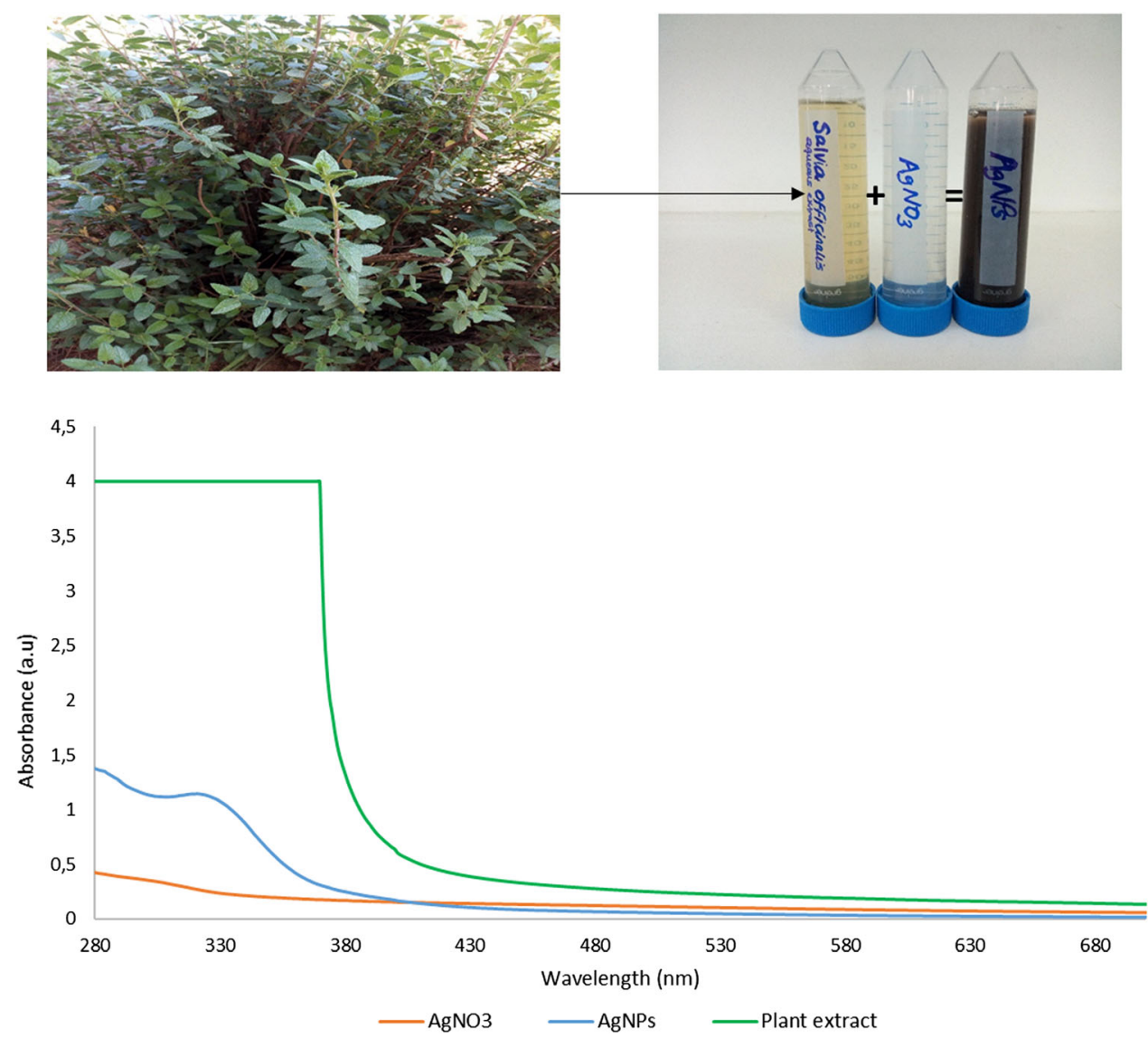

closely related result from AgNPs synthesized from aerial extract of Origanum vulgare in which the absorbance peak was at $320 \mathrm{~nm}$.

\section{TEM, SEM, EDX and TGA Analyses}

Transmission electron microscope image of AgNPs depicted in Fig. 2a reveals that the bulk of the AgNPs were spherical in shape with average size of $41 \mathrm{~nm}$ without agglomeration. Findings from this present study concur with the sizes of other reported biosynthesized AgNPs from some medicinal plants in previous studies [33, 36, 54]. Furthermore, TEM results from this study confirmed that AgNPs were polydispersed with spherical shape [31]. SEM image (Fig. 2b) of AgNPs showed irregular structures with clusters. Report from previous studies highlighted that spherical-shaped nanoparticles are more effective than rodlike or hexagonally shaped nanoparticles [55]. Biological activity of AgNPs mostly depends its size and surface area; smaller nanoparticles have larger surface area than those larger ones [56]. In addition, elemental compositions analysis was carried out with EDX, and the three major elements in the AgNPs is represented in Fig. 2c. The predominant elements include carbon, oxygen and silver and our findings agree with the results of Mishra et al. [57]. The
EDX analysis showed a strong signal for silver particles at 2.70 and $3.0 \mathrm{keV}$ which further confirmed the presence of $\mathrm{Ag}$ with percentage weight and atomic of 60.97 and $17.66 \%$, respectively. Furthermore, intense peaks of carbon and oxygen between 0.0 and $0.5 \mathrm{keV}$ further confirmed that phytochemical compounds stabilizing AgNPs originated from aqueous extract of $S$. officinalis. Thermogravimetric analysis reveals that AgNPs retained about $50 \%$ of its initial weight after subjected to $900{ }^{\circ} \mathrm{C}$ (Fig. 2d). The initial weight loss at $350{ }^{\circ} \mathrm{C}$ could be to the moisture content in AgNPs and further weight loss observed revealed the decomposition of the organic compounds in AgNPs, which indicates the thermo-sensitive (at high temperatures) nature of the phytochemical compounds capping the AgNPs.

\section{FTIR Analysis}

In order to identify the phytochemical compounds from $S$. officinalis extract responsible for the reduction of $\mathrm{AgNO}_{3}$ and those involved in the capping and stabilizing of AgNPs, FTIR analysis was carried out and the result is depicted in Fig. 3. In this study, S. officinalis extract showed several spectra that indicate the complex nature of the plant extract and our findings corroborates with the results of Al-Sheddi et al. [35]. The spectra of S. officinalis 

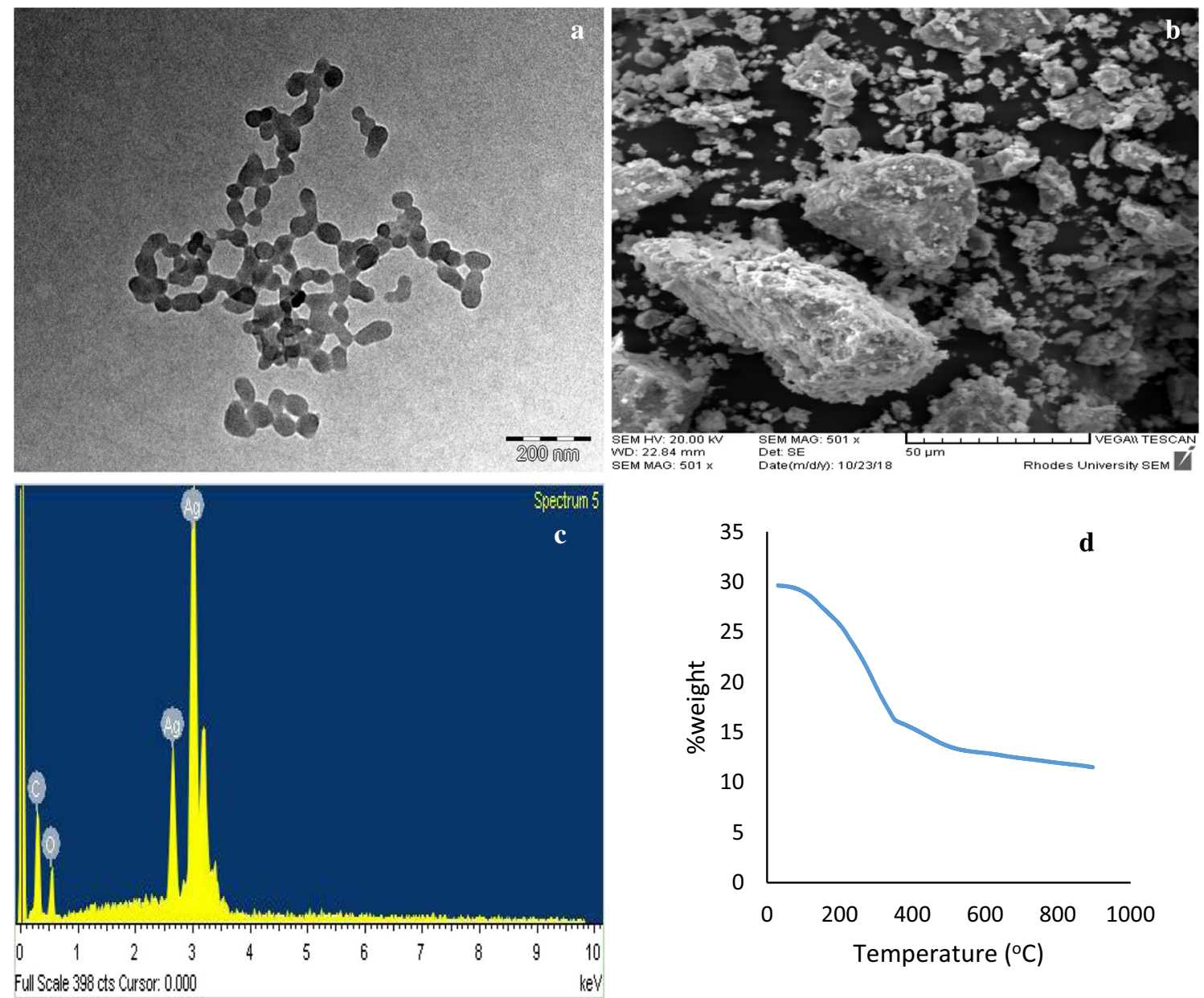

Fig. 2 TEM image (a), SEM image (b), EDX analysis (c) and TGA analysis (d) of AgNPs from S. officinalis

extracts displayed broad and strong absorbance peak at $3248 \mathrm{~cm}^{-1}$ that corresponds to $\mathrm{O}-\mathrm{H}$ vibration, which could be arising from phenolic compounds or carboxylic group in the extract [58]. The peak spectrum at $2918.9 \mathrm{~cm}^{-1}$ is assigned to the stretching vibration of $\mathrm{CH}_{2}$ group [59], vibration peak at $1683 \mathrm{~cm}^{-1}$ indicates $\mathrm{C}=\mathrm{O}$ stretching or $\mathrm{C}-\mathrm{N}$ bending in the amide group respectively [35]. The spectra peaks of AgNPs at $3895 \mathrm{~cm}^{-1}, 3739 \mathrm{~cm}^{-1}$, $2842 \mathrm{~cm}^{-1}, \quad 2312 \mathrm{~cm}^{-1}, \quad 2102 \mathrm{~cm}^{-1}, \quad 1900 \mathrm{~cm}^{-1}$, $1683 \mathrm{~cm}^{-1}, 1566 \mathrm{~cm}^{-1}, 1215 \mathrm{~cm}^{-1}$ and $1006 \mathrm{~cm}^{-1}$ indicate a shift in absorption bands of the phytochemical compounds from aqueous extract of $S$. officinalis stabilizing it. These observations agree with the reports of other researchers in the literature $[60,61]$.

\section{XRD Analysis}

$\mathrm{X}$-ray diffraction analysis represented in Fig. 4 revealed the unique Bragg reflection values of AgNPs; $28.02^{\circ}$, $38.29^{\circ}, 44.50^{\circ}, 64.69^{\circ}$ and $77.60^{\circ}$ at $2 \theta$ angle, which matched to $110,111,200,220$ and 311 , indicating the face- centered cubic (FCC) crystalline structure of the AgNPs synthesized using aqueous extract of $S$. officinalis as the reducing and stabilizing agent. The strong peak at $38.29^{\circ}$ signifies a high level of crystallinity $[62,63]$. According to the report of Krishnaraj et al. [29], the high peaks at $32.51^{\circ}$ and $44.50^{\circ}$ in the XRD spectra could be due to the presence of phytochemical compounds in the aqueous extract of the plant coating the surface of the synthesized AgNPs and stabilizing it. Other unidentified peaks observed in the XRD spectra could be to the presence of some organic compounds originating from the aqueous extract of $S$. officinalis [64]. Our findings are in agreement with the results of Carmona et al. [58] and Kamaraj et al. [65] in which the XRD peaks of the biosynthesized AgNPs were corresponds to (111), (200), (220) and (311) of cubic crystalline silver.

\section{Cytotoxicity Effect of AgNPs on HeLa Cells}

Remarkable increase in the fabrication of metallic nanoproducts over the years has made researchers in the 
Fig. 3 FTIR analysis of aqueous leaf extract of $S$. officinalis (a) and AgNPs (b)
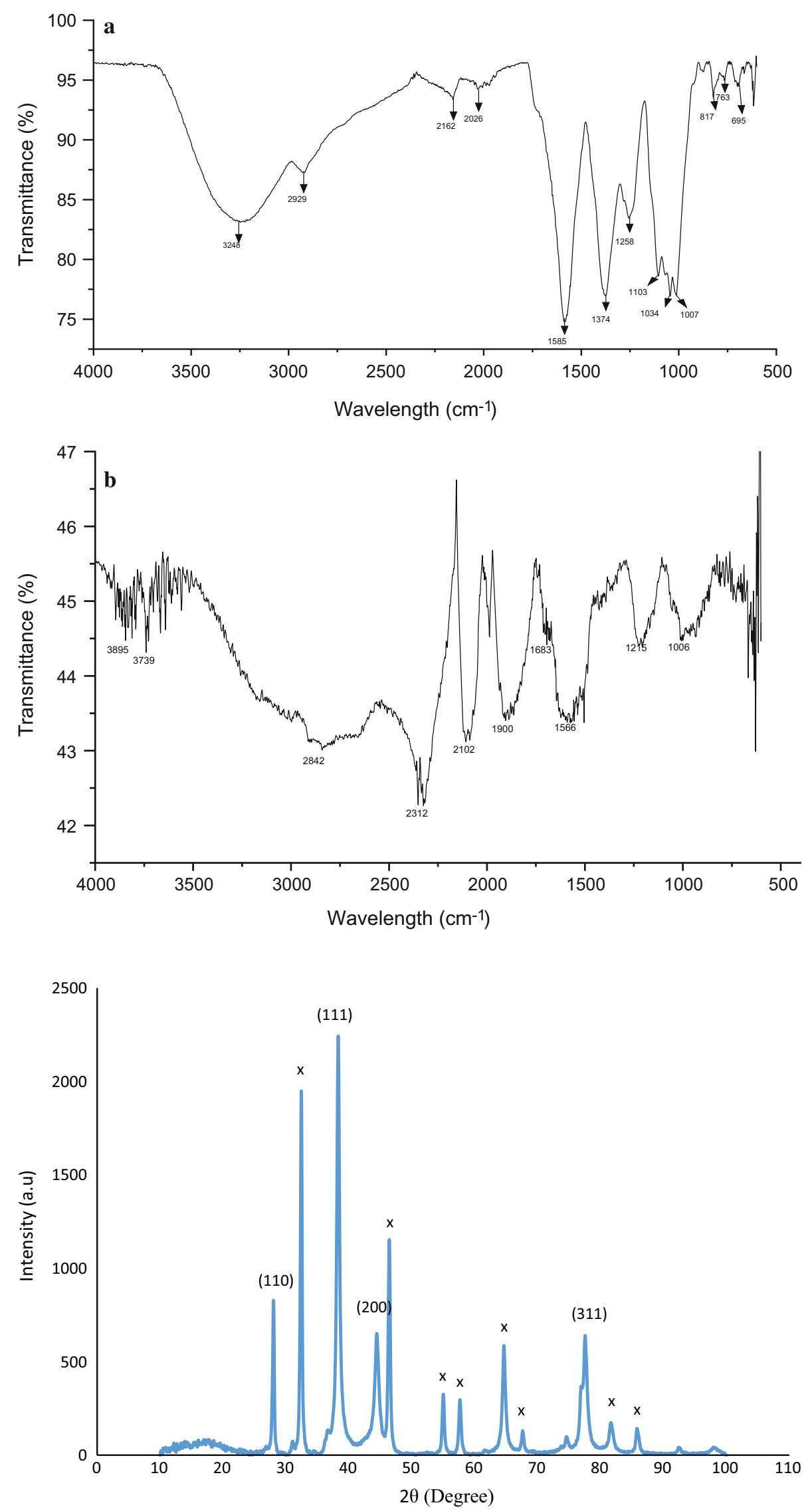

Fig. 4 XRD pattern of AgNPs from aqueous extract of $S$. officinalis $(\mathrm{x}$-denote unidentified peaks that could be resulting from the organic compound from the aqueous extract of the $S$. officinalis) 


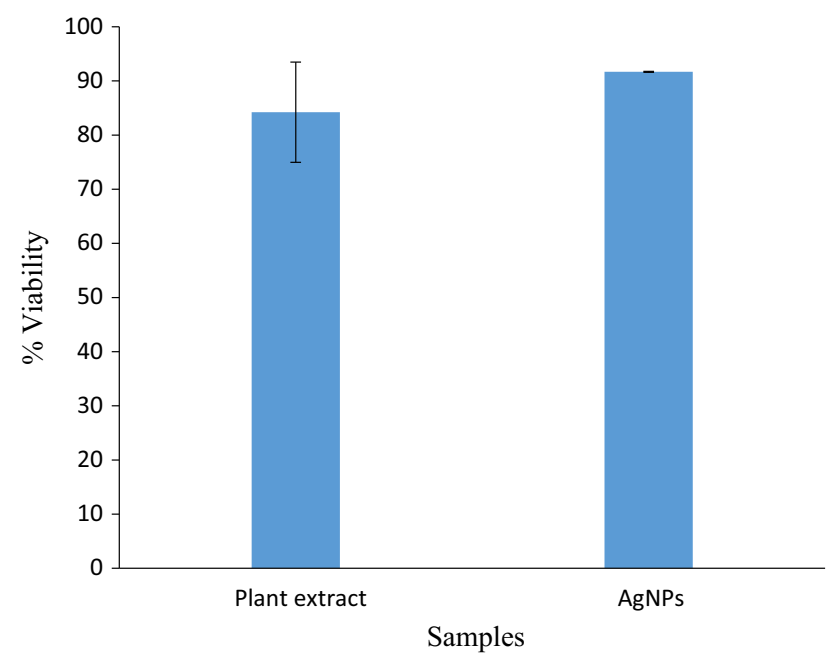

Fig. 5 Percentage viability of HeLa cells incubated with $50 \mu \mathrm{g} / \mathrm{mL}$ aqueous leaf extract of $S$. officinalis and AgNPs for $48 \mathrm{~h}$. Error bars indicate standard deviation of triplicate wells

field to be mindful about their safety. As emphasized by Barabadi et al. [66], there are several factors that influence cytotoxicity of silver nanoparticles and these factors include among others, size distribution, morphology, surface charge, surface chemistry, capping agents. The potential of plant-mediated AgNPs in clinical marketability needs to be assessed in order to ensure their toxicity to mammalian cells. Previous studies have highlighted that AgNPs have ability to induce reactive oxygen species (ROS) that cause DNA damage and chromosomal fragmentation, interfere with protein normal function by affecting the purine and pyrimidine bases, which consequently lead to gene mutation and affect the gene expression profiles [67-69]. Therefore, it is highly imperative to determine the toxicity level of the plant fabricated AgNPs in the present study. Hence, prior to the antiplasmodial assay, the cytotoxic effect of AgNPs on HeLa cells was assessed and it was observed that at $50 \mu \mathrm{g} / \mathrm{mL}$, both the aqueous extract of $S$. officinalis and the AgNPs displayed low cytotoxicity on HeLa cells, producing percentage cell viabilities compared to untreated controls of $84 \pm 9$ and $92 \pm 0.1$, respectively (Fig. 5). Contrary to our findings, the biosynthesized AgNPs from some medicinal plants such as Melia azedarach [70], Moringa olifera [71], Nepeta deflersiana [35] in the previous studies showed high cytotoxic effect on HeLa cells.

\section{Antiplasmodial Activity Assay}

Nanoparticles have presented an innovative approach for drug delivery efficiency because of their reduced size and large surface area to volume ratio, which aids their ability to penetrate the cell membrane [64]. The development of effective and reliable drugs in the fight against malaria represents a crucial challenge in modern parasitology [65]. Phytochemical compounds that demonstrate high antiplasmodial activity could effective serve as alternative to synthetic antimalarial drugs [72]. The results of the antiplasmodial activity of both the aqueous extract $S$. officinalis and AgNPs are depicted in Fig. 6. High parasite viability was observed in the cells treated with $50 \mu \mathrm{g} / \mathrm{mL}$ of the aqueous extract of $S$. officinalis which signifies low antiplasmodial activity, compared to AgNPs that completely killed the parasites at this concentration. A doseresponse assay yielded an antiplasmodial $\mathrm{IC}_{50}$ of $3.6 \mu \mathrm{g} /$ $\mathrm{mL}$ for the AgNPs. This knowledge of antiplasmodial activity of $\mathrm{AgNPs}$ based on the reported $\mathrm{LC}_{50}$ values would
Fig. 6 Antiplasmodial activity of AgNPs synthesized from aqueous leaf extract of $S$. officinalis

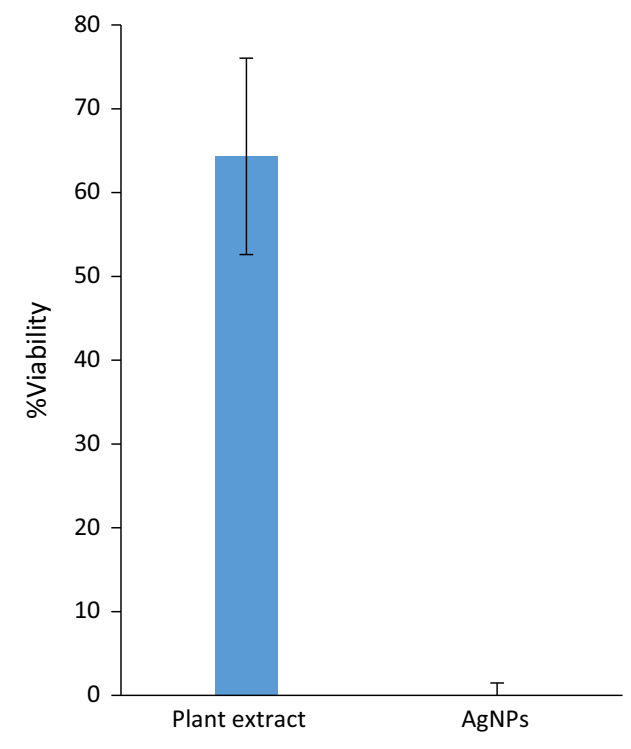


be helpful in understanding their antimalarial properties as well. The result obtained from our study is higher than most antiplasmodial activity of plant-based silver nanoparticles documented in the previous studies [49, 73, 74]. Similarly, studies on the antiplasmodial activity of AgNPs from some medicinal plants such as Chrysanthemum indicum [31], Ceropegia thwaitesii [32], Datura metel [75], Avicennia marina [76], Belosynapsis kewensis [77], Murraya koenigii [65], Rubus ellipticus [48], Holarrhena antidysenterica [64] have been documented.

\section{Conclusions}

In this present study, a one-step, simple and reproducible green approach was used for the synthesis of AgNPs using the aqueous leaf extract of $S$. officinalis. The method was found to be fast, cost-effective and environmentally benign. Different spectroscopy analyses were used to confirm the synthesis of AgNPs and TEM analysis revealed its average size to be $41 \mathrm{~nm}$ and spherical-shaped with some irregular structures. The XRD results showed that the AgNPs were crystalline in nature and FTIR revealed some key phytochemical compounds acting as capping and stabilizing agent. AgNPs demonstrated good antiplasmodial activity with a low micromolar $\mathrm{IC}_{50}$, while cytotoxicity against HeLa cells at $50 \mu \mathrm{g} / \mathrm{mL}$ was mild. Findings from this study indicate that AgNPs could be a lead compound in the development of a novel antimalarial drug and further studies on the mechanism of action is highly imperative.

Acknowledgements We would like to extend our profound gratitude to South African Medical Research Council "Grant no. SAMRC/ UFH/P790" and University of Fort Hare "Post-Doctoral Seed-grant no. C324" for their financial support.

Authors' Contributions KO conceptualized and executed the research as well as drafted the first manuscript; $\mathrm{HH}$ carried out the toxicity studies, edited and proofread the manuscript; AIO provides the resources and supervised the research. All authors proofread the manuscript and approved the submission of the final version for publication.

\section{Compliance with Ethical Statement}

Conflict of interest The authors declare that there is no conflict of interest.

Open Access This article is licensed under a Creative Commons Attribution 4.0 International License, which permits use, sharing, adaptation, distribution and reproduction in any medium or format, as long as you give appropriate credit to the original author(s) and the source, provide a link to the Creative Commons licence, and indicate if changes were made. The images or other third party material in this article are included in the article's Creative Commons licence, unless indicated otherwise in a credit line to the material. If material is not included in the article's Creative Commons licence and your intended use is not permitted by statutory regulation or exceeds the permitted use, you will need to obtain permission directly from the copyright holder. To view a copy of this licence, visit http://creativecommons. org/licenses/by/4.0/.

\section{References}

1. J. Jeevanandam, A. Barhoum, Y. S. Chan, A. Dufresne, and M. K. Danquah (2018). Beilstein J. Nanotechnol. 9, 1050.

2. V. Varadharaj, A. Ramaswamy, R. Sakthivel, R. Subbaiya, H. Barabadi, M. Chandrasekaran, and M. Saravanan (2019). J. Clust. Sci. https://doi.org/10.1007/s10876-019-01732-3.

3. S. Bhatnagar, T. Kobori, D. Ganesh, K. Ogawa, and H. Aoyagi (2019). Nanomaterials 9, 1042.

4. R. Balachandar, P. Gurumoorthy, N. Karmegam, H. Barabadi, R. Subbaiya, K. Anand, P. Boomi, and S. Muthupandian (2019). J. Clust. Sci. 30, 1481

5. S. Preet and N. Satsangi (2019). J. Clust. Sci. 30, 1611.

6. P. Jamdagni, P. Khatri, and J. S. Rana (2018). J. King Saud Univ. Sci. 30, 168.

7. P. Singh, S. Ahn, J. P. Kang, S. Veronika, Y. Huo, H. Singh, M. Chokkaligam, M. El-AgamyFarh, V. C. Aceituno, Y. J. Kim, and D. C. Yang (2018). Artif. Cells Nanomed. Biotechnol. 46, 2022.

8. E. G. Haggag, A. M. Elshamy, M. A. Rabeh, N. M. Gabr, M. Salem, K. A. Youssif, A. Samir, A. B. Muhsinah, A. Alsayari, and U. R. Abdelmohsen (2019). Int. J. Nanomed. 14, 6217.

9. J. Udayabhanu, V. Kannan, M. Tiwari, G. Natesan, B. Giovanni, and V. Perumal (2018). J. Photochem. Photobiol. 178, 496.

10. World Health Organization. World malaria report. 2019. [accessed on March 27, 2019]. Available from: https://www.who.int/ news-room/fact-sheets/detail/malaria.

11. B. Watkins (2003). Trends Parasitol. 19, 477.

12. S. Ponarulselvam, C. Panneerselvam, K. Murugan, N. Aarthi, K. Kalimuthu, and S. Thangamani (2012). Asian Pac. J. Trop. Biomed. 2, 574.

13. F. Bray, J. Ferlay, I. Soerjomataram, R. L. Siegel, L. A. Torre, and A. Jemal (2018). CA Cancer J. Clin. 68, 394.

14. P. A. Cohen, A. Jhingran, A. Oaknin, and L. Denny (2019). Lancet 393, 169.

15. WHO (2018). http://www.who.int/cancer/prevention/diagnosisscreening/cervical-cancer/en/ (accessed April 25, 2018).

16. E. J. Crosbie, M. H. Einstein, S. Franceschi, and H. C. Kitchener (2013). Lancet 382, 889.

17. L.A.G. Ries, D. Melbert, M. Krapcho et al. (2007). National Cancer Institute: Bethesda, MD, USA, Cervical cancer 1975.

18. W. Small Jr., M. A. Bacon, A. Bajaj, et al. (2017). Cancer 123, 2404.

19. D. J. Newman and G. M. Cragg (2012). J. Nat. Prod. 75, 311.

20. M. G. Guzmán, J. Dille, and S. Godet (2009). Int. J. Chem. Biomol. Eng. 2009, (2), 104.

21. J. Daphne, A. Francis, R. Mohanty, N. Ojha, and N. Das (2018). Res. J. Pharm. Technol. 11, 83.

22. R. A. Sheldon (2012). Chem. Soc. Rev. 41, 1437.

23. G. Bagherzade, M. M. Tavakoli, and M. H. Namaei (2017). Asian Pac. J. Trop. Biomed. 7, 227.

24. M. Sastry, A. Ahmad, M. I. Khan, and R. Kumar (2003). Curr. Sci. 85, 162.

25. K. S. Kavitha, B. Syed, D. Rakshith, H. U. Kavitha, H. C. Yashwantha Rao, et al. (2013). Int. Res. J. Biol. Sci. 2, 66.

26. T. Y. Fahmy and F. Mobarak (2011). Int. J. Biol. Macromol. 48, 134.

27. P. P. N. V. Kumar, S. V. N. Pammi, P. Kollu, K. V. V. Satyanarayana, and U. Shameem (2014). Ind. Crops Prod. 52, 562. 
28. M. Behravan, A. H. Panahib, A. Naghizadeh, M. Ziaeed, R. Mahdavi, and A. Mirzapour (2019). Int. J. Biol. Macromol. 124, 148.

29. C. Krishnaraj, E. G. Jagan, S. Rajasekar, P. Selvakumar, P. T. Kalaichelvan, and N. Mohan (2010). Colloid Surf. B Biointerfaces 76, 50.

30. A. K. Mittal, Y. Chisti, and U. C. Banerjee (2013). Biotechnol. Adv. 31, 346.

31. S. Arokiyaraj, V. D. Kumar, V. Elakya, T. Kamala, S. K. Park, M. Ragam, M. Saravanan, M. Bououdina, M. V. Arasu, K. Kovendan, and S. Vincent (2015). Environ. Sci. Pollut. Res. 22, 9759.

32. S. Muthukrishnan, S. Bhakya, S. T. Kumar, and M. V. Rao (2015). Ind. Crop Prod. 63, 119.

33. M. Gomathi, P. V. Rajkumar, A. Prakasam, and K. Ravichandran (2017). Resour. Effic. Technol. 3, 280.

34. G. Lakshmanan, A. Sathiyaseelan, P. T. Kalaichelvan, and K. Murugesan (2018). Karbala Int. J. Mod. Sci. 4, 61.

35. E. S. Al-Sheddi, N. N. Farshori, M. M. Al-Oqail, S. M. AlMassarani, Q. Saquib, R. Wahab, J. Musarrat, A. A. Al-Khedhairy, and M. A. Siddiqui (2018). Bioinorg. Chem. Appl. 12, 9390784.

36. A. A. Alyousef, M. Arshad, R. AlAkeel, and A. Alqasim (2019). Biotechnol. Biotechnol. Equip. 33, 931.

37. K. Kanagamani, P. Muthukrishnan, K. Shankar, A. Kathiresan, H. Barabadi, and M. Saravanan (2019). J. Clust. Sci. 30, 1415.

38. R. G. Ridley (2002). Nature 415, 686.

39. H. Yuan, Q. Ma, L. Ye, and G. Piao (2016). Molecules 21, 559.

40. C. M. Nicolescu, R. L. Olteanu, and M. Bumbac (2017). Anal. Lett. 50, 2802.

41. W. K. B. Khalil, F. Abdu, and C. Biology (2013). World Appl. Sci. J. 24, 826.

42. F. Namvar, M. Suhaila, S. G. Fard, and J. Behravan (2012). Food Chem. 130, 376.

43. S. Pirtarighat, M. Ghannadnia, and S. Baghshahi (2019). J. Nanostruct. Chem. 9, 1.

44. J. Baharara, T. Ramezani, and M. Mousavi (2017). Ann. Trop. Med. Public Health 10, 1265.

45. K. Okaiyeto, M. O. Ojemaye, H. Hoppe, L. V. Mabinya, and A. I. Okoh (2019). Molecules 24, 4382.

46. G. T. Keusch, M. Jacewicz, and S. Z. Hirschman (1972). J. Infect. Dis. 125, 539.

47. M. T. Makler, J. M. Ries, J. A. Williams, J. E. Bancroft, R. C. Piper, B. L. Gibbins, and D. J. Hinrichs (1993). Am. J. Trop. Med. Hyg. 48, 739.

48. F. S. AlQahtani, M. M. AlShebly, M. Govindarajan, S. Senthilmurugan, P. Vijayan, and G. Benelli (2017). J. Asia Pac. Entomol. 20, 157.

49. R. Larayetan, M. O. Ojemaye, O. O. Okoh, A. Sadimenko, and A. I. Okoh (2019). Green Chem. Lett. Rev. 12, 61.

50. L. Mulfinger, S. D. Solomon, M. Bahadory, A. V. Jeyarajasingam, S. A. Rutkowsky, and C. Boritz (2007). J. Chem. Educ. 84, 322.

51. J. G. Parsons, J. R. Peralta-Videa, and J. L. Gardea-Torresdey (2007). Dev. Environ. Sci. 5, 463.

52. F. Zia, N. Ghafoor, M. Iqbal, and S. Mehboob (2016). Appl. Nanosci. 6, 1023.

53. M. R. Shaik, M. Khan, M. Kuniyil, A. Al-Warthan, H. Z. Alkhathlan, M. R. H. Siddiqui, J. P. Shaik, A. Ahamed, A. Mahmood, M. Khan, and S. F. Adil (2018). Sustainability 10, 913.
54. U. Muthukumaran, M. Govindarajan, M. Rajeswary, and S. L. Hoti (2015). Parasitol. Res. 114, 1817.

55. Y. Zhao, Y. Wang, F. Ran, Y. Cui, C. Liu, Q. Zhao, Y. Gao, D. Wang, and S. Wang (2017). Sci. Rep. 7, 4131.

56. K. C. Hembram, R. Kumar, L. Kandha, P. K. Parhi, C. N. Kundu, and B. K. Bindhani (2018). Artif. Cells Nanomed. Biotechnol. 46, S38.

57. S. Mishra, B. R. Singh, A. H. Naqvi, and H. B. Singh (2017). Sci. Rep. 7, 45154.

58. E. R. Carmona, N. Benito, T. Plaza, and G. Recio-Sánchez (2017). Green Chem. Lett. Rev. 10, 250.

59. J. Ding, G. Chen, G. Chen, and M. Guo (2019). Pharmaceutics 11, 123.

60. V. Kathiravan, S. Ravi, and S. Ashokkumar (2014). Spectrochim. Acta A 130, 116.

61. M. M. I. Masum, M. M. Siddiqa, K. A. Ali, Y. Zhang, Y. Abdallah, E. Ibrahim, W. Qiu, C. Yan, and B. Li (2019). Front. Microbiol. 10, 820.

62. S. Pattanayak, M. M. R. Mollick, D. Maity, S. Chakraborty, S. K. Dash, S. Chattopadhyay, S. Roy, D. Chattopadhyay, and M. Chakraborty (2017). J. Saudi Chem. Soc. 21, 673.

63. N. Basavegowda and Y. Rok-Lee (2014). Mater. Lett. 109, 31.

64. D. Kumar, G. Kumar, R. Das, and V. Agrawal (2018). Process Saf. Environ. 116, 137.

65. C. Kamaraj, G. Balasubramani, C. Siva, M. Raja, V. Balasubramanian, R. K. Raja, S. Tamilselvan, G. Benelli, and P. Perumal (2017). J. Clust. Sci. 28, 1667.

66. H. Barabadi, M. Najafi, H. Samadian, A. Azarnezhad, H. Vahidi, M. A. Mahjoub, M. Koohiyan, and A. Ahmadi (2019). Medicina $\mathbf{5 5}, 439$.

67. Z. Magdolenova, A. Collins, A. Kumar, A. Dhawan, V. Stone, and M. Dusinska (2014). Nanotoxicology 8, 233.

68. N. Mahaye, M. Thwala, D. A. Cowan, and N. Musee (2017). Mutat. Res. 773, 134.

69. N. Singh, B. Manshian, G. J. Jenkins, S. M. Griffiths, P. M. Williams, T. G. Maffeis, C. J. Wright, and S. H. Doak (2009). Biomaterials 30, 3891.

70. R. Sukirtha, K. M. Priyanka, J. J. Antony, S. Kamalakkannan, R. Thangamb, P. Gunasekaran, M. Krishnan, and S. Achiraman (2012). Proc. Biochem. 47, 273.

71. K. Vasanth, K. Ilango, R. MohanKumara, A. Agrawal, and D. P. Govind (2014). Colloids Surf. B. Biointerfaces 117, 354.

72. M. Govindarajan, M. Rajeswary, K. Veerakumar, U. Muthukumaran, S. L. Hoti, and G. Benelli (2016). Exp. Parasitol. 161, 40.

73. M. Sardana, V. Agarwal, A. Pant, V. Kapoor, K. C. Pandey, and S. Kumar (2018). Asian Pac. J. Trop. Biomed. 8, 268.

74. C. Panneerselvam, K. Murugan, and D. Amerasan (2015). Adv. Mater. Res. 1086, 11.

75. K. Murugan, D. Dinesh, P. J. Kumar, C. Panneerselvam, J. Subramaniam, P. Madhiyazhagan, U. Suresh, M. Nicoletti, A. A. Alarfaj, M. A. Munusamy, A. Higuchi, H. Mehlhorn, and G. Benelli (2015). Parasitol. Res. 114, 4645.

76. S. Balakrishnan, M. Srinivasan, and J. Mohanraj (2016). J. Parasites Dis. 403, 991.

77. R. Bhuvaneswari, R. J. Xavier, and M. Arumugam (2016). J. King Saud Univ. Sci. 28, 318.

Publisher's Note Springer Nature remains neutral with regard to jurisdictional claims in published maps and institutional affiliations. 